\title{
The Mu-Opioid Receptor and the NMDA Receptor Associate in PAG Neurons: Implications in Pain Control
}

\author{
María Rodríguez-Muñoz', Pilar Sánchez-Blázquez ${ }^{1,2}$, Ana Vicente-Sánchez ${ }^{2}$, Esther Berrocoso ${ }^{1,3}$ and \\ Javier Garzón*, 1,2 \\ 'CIBER of Mental Health (CIBERSAM), ISCIII, Madrid, Spain; '2Department of Neuropharmacology, Cajal Institute, CSIC, Madrid, Spain; \\ ${ }^{3}$ Department of Neuroscience, Faculty of Medicine, University of Cadiz, Cadiz, Spain
}

\begin{abstract}
The capacity of opioids to alleviate inflammatory pain is negatively regulated by the glutamate-binding N-methyl-D-aspartate receptor (NMDAR). Increased activity of this receptor complicates the clinical use of opioids to treat persistent neuropathic pain. Immunohistochemical and ultrastructural studies have demonstrated the coexistence of both receptors within single neurons of the CNS, including those in the mesencephalic periaqueductal gray (PAG), a region that is implicated in the opioid control of nociception. We now report that mu-opioid receptors (MOR) and NMDAR NRI subunits associate in the postsynaptic structures of PAG neurons. Morphine disrupts this complex by protein kinase-C (PKC)-mediated phosphorylation of the NRI CI segment and potentiates the NMDAR-CaMKII, pathway that is implicated in morphine tolerance. Inhibition of PKC, but not PKA or GRK2, restored the MOR-NRI association and rescued the analgesic effect of morphine as well. The administration of N-methyl-D-aspartic acid separated the MOR-NRI complex, increased MOR Ser phosphorylation, reduced the association of the MOR with G-proteins, and diminished the antinociceptive capacity of morphine. Inhibition of PKA, but not PKC, CaMKII, or GRK2, blocked these effects and preserved morphine antinociception. Thus, the opposing activities of the MOR and NMDAR in pain control affect their relation within neurons of structures such as the PAG. This finding could be exploited in developing bifunctional drugs that would act exclusively on those NMDARs associated with MORs.

Neuropsychopharmacology (2012) 37, 338-349; doi:I0.1038/npp.20II.155; published online 3 August 20II
\end{abstract}

Keywords: mu-opioid receptor; N-methyl-D-aspartate receptor; periaqueductal gray; pain; analgesia; receptor association

\section{INTRODUCTION}

The glutamate $N$-methyl-D-aspartate receptor (NMDAR) is essential to the function of the nervous system, and therefore its de-regulation contributes to the pathophysiology of many neurological disorders. These include neurodegenerative diseases, such as Alzheimer's disease, Parkinson's disease, multiple sclerosis, and amyotrophic lateral sclerosis (Lipton, 2006), and mood disorders, such as schizophrenia and depression (Mechri et al, 2001; Maeng and Zarate, 2007). The persistent activation of NMDARs is also responsible for the neural changes accompanying different variants of neuropathic pain, including nerve injury-induced neuropathy, diabetic neuropathy, chronic inflammatory pain, cancer pain, and post-herpetic pain. In these conditions of persistent pain, mu-opioid receptor (MOR)-activating opioids do not provide efficacious relief (Chapman et al, 1994; Sigtermans et al,

*Correspondence: Dr J Garzón, Department of Neuropharmacology, Instituto Cajal, CSIC, Avd. Dr. Arce 37, Madrid 28002, Spain, Tel: + 34 9l 585 4733, Fax: + 34 9l 585 4754,

E-mail: jgarzon@cajal.csic.es

Received 27 May 20I I; revised 8 July 20 II; accepted 8 July 20I I
2009). Thus, to treat neuropathic pain in the clinic, opioid doses must be substantially increased beyond those effective against nociceptive pain, and the relief is, in most cases, only partial. Neuropathic pain is characterized by tactile allodynia and hyperalgesia, which remit with drug treatments that block NMDAR function, for example, ketamine, methadone, and memantine (Mizoguchi et al, 2009). Although drugs that block NMDAR channel permeation improve or prolong opioid analgesia in humans, because of their lack of selectivity for those receptors involved in nociception, they produce a series of unacceptable drawbacks, such as drowsiness, hallucinations, and even coma (Palmer, 2001). Therefore, opioids are usually combined with antidepressants, anticonvulsants, or sodium channel blockers to increase their clinical effectiveness (reviewed by Mizoguchi et al, 2009). Certainly, a better understanding of the cross-talk that operates between MOR and NMDAR to regulate nociception would improve the efficacy and selectivity of therapies used to treat debilitating neuropathic pain.

The observation that MOR-acting opioids are of limited efficacy in neuropathic pain is supported by pharmacological and molecular studies indicating that morphine analgesia is 
under negative functional regulation by the NMDAR-neural nitric oxide synthase (nNOS) cascade (Inoue et al, 2003; Rodríguez-Muñoz et al, 2008). However, the relationship between MORs and NMDARs is bidirectional, and tolerance to morphine develops as a consequence of MOR-induced potentiation of NMDAR-calcium and calmodulin-dependent kinase-II (CaMKII) activity (Trujillo, 2002; Garzón et al, 2008). Indeed, MOR-acting opioids regulate glutamate-activated NMDAR currents in different areas of the nervous system, including the thalamus (Narita et al, 2008), nucleus coeruleus (Koyama and Akaike, 2008), brainstem medulla (Chen and Huang, 1991; Kow et al, 2002), and spinal dorsal horn neurons (Rusin and Randic, 1991). Most relevantly, acute opioid administration increases NMDAR function in neurons with opioid receptors (Martin et al, 1997; Przewlocki et al, 1999).

Anatomical studies have shown that MORs and NMDARs colocalize in many regions of the CNS, including patches within spiny neurons of the caudate putamen, the habenular nucleus, the spinal cord dorsal horn, the shells of the nucleus accumbens, and neurons of solitary tract nucleus. Importantly, these two receptors colocalize on single neurons within the CNS (reviewed by Trujillo, 2002), and at the ultrastructural level both receptors show convincing colocalization (Glass et al, 2009). Specifically, the midbrain periaqueductal gray (PAG) is densely innervated by glutamatergic projections from the forebrain, and there is robust MOR-NMDAR colocalization in the dendrites and somata of ventrolateral PAG neurons (Commons et al, 1999; Narita et al, 2008). The PAG is of physiological relevance to the nociceptive modulation network that operates both at the supraspinal level and through dorsal horn interneurons (Mansour et al, 1988; Marinelli et al, 2002). Deep brain stimulation targeting the PAG produces analgesia through the action of endogenous opioids on PAG MORs (Barbaro, 1988). This therapy has successfully been used to treat intractable pain in humans, including phantom limb pain, post-herpetic neuralgia, and diverse neuropathies (Bittar et al, 2005; Owen et al, 2007).

Therefore, the current literature convincingly demonstrates that the MOR and the NMDAR coexist at certain postsynapses and that both receptors show an electrophysiological interaction in individual neurons. Therefore, MOR-NMDAR cross-regulation in pain control could be consequence of their presence in the same neuronal compartment without ruling out that direct interaction occurs. This last possibility is of special interest because it would provide a suitable substrate to develop more specific regulators of MOR-NMDAR function. With this in mind, we assessed whether MORs and NMDARs establish an association in PAG synaptosomes and analyzed the manner in which their agonists, morphine and NMDA, and a series of Ser/Thr kinases regulate this relationship.

\section{MATERIALS AND METHODS}

Preparation and Solubilization of the PAG Synaptoneurosome-Enriched Fraction. MOR Immunoprecipitation and Co-Precipitation of Associated Proteins

Procedures involving mice strictly followed the guidelines of the European Community for the Care and Use of
Laboratory Animals (Council Directive 86/609/EEC) and Spanish Law (RD 1201/2005) regulating animal research. The experimental protocols were reviewed and approved by the Committee for Animal Experimentation at the CSIC.

Experimental tissue was obtained from male albino CD1 mice (Charles River, Barcelona, Spain) weighing 22-27g. For immunoprecipitation studies, the PAG from eight mice was typically pooled. The assays were repeated at least twice on samples that had received an identical opioid treatment and were collected at the same interval after opioid administration. The methods used to prepare the PAG synaptosomal fraction have been described elsewhere (Rodríguez-Muñoz et al, 2007b). The affinity-purified IgGs against the extracellular domains of the MOR 2EL (205-216: MATTKYRQGSID; GenScript, NJ, USA) and of the NMDAR NR1 subunit (483-496: KFGTQERVNNSNKK; SigmaGenosys, Cambridge, UK) were labeled with biotin (Pierce \#21217 and 21339). Pilot assays were performed to optimize the amount of IgG and sample protein needed to precipitate the desired protein in a single run. Target proteins were then immunoprecipitated from solubilized membranes and resolved by SDS/PAGE as described previously (Garzón et al, 2005a). The separated proteins were then transferred onto $0.2 \mu \mathrm{m}$ PVDF membranes and probed with the selected antibodies in DecaProbe chambers (PR 150; Hoefer-GE, Barcelona, Spain).

To assess the morphine-induced Ser phosphorylation of MORs, the existing protein interactions were disrupted under denaturing conditions prior to immunoprecipitation (Rodríguez-Muñoz et al, 2007b). Afterwards, MORs were detected with the MOR CT antibody and phosphoserines were detected with a mouse monoclonal antibody (IgM, 1:1000; Calbiochem; clone 1C8 525281).

\section{Detection of Signaling Proteins}

The specificity and efficacy of the antibodies used in immunoprecipitation assays from mouse brain synaptosomes have been addressed elsewhere (Garzón et al, 2005b; Rodríguez-Muñoz et al, 2011b; Garzón et al, 2011). These antibodies fulfill the recommended criteria for use in western blotting as well (Saper and Sawchenko, 2003). All the antibodies (see Supplementary information) were diluted in TBS $+0.05 \%$ Tween-20 (TTBS) and incubated with the PVDF membranes for $24 \mathrm{~h}$ at $6{ }^{\circ} \mathrm{C}$. The secondary antisera were incubated for $2-3 \mathrm{~h}$ and visualized by using the Immobilon Western Chemiluminiscent HRP substrate (Millipore; \#WBKLS0100). Chemiluminescence was recorded with a ChemiImager IS-5500 (Alpha Innotech, San Leandro, CA, USA). Densitometry was performed by using the Quantity One Software (Bio-Rad) and expressed as the mean of the integrated volume after subtracting the background (average optical density of the pixels within the object area $\left./ \mathrm{mm}^{2}\right)$.

Expression of C-Terminal Sequences of MOR1, MOR1C, NR1(C0-C1-C2), and NR1(C0-C2) Splice Variants

The KRX/pFN2A-MOR1 (C-terminus), KRX/pET151MOR1C (C-terminus), KRX/pFN2A-NR1 (segments C0$\mathrm{C} 2$ ), and NR1 (segments $\mathrm{C} 0-\mathrm{C} 1-\mathrm{C} 2$ ) strains were grown to an optical density of 0.5-0.6. IPTG (Promega; \#V3955) and 
Rhamnose (Promega; \#L5701) were added at a final concentration of $1 \mathrm{mM}$ and $0.1 \%$, respectively. After overnight induction at room temperature, the cells were collected by centrifugation and the pellets were kept at $-20{ }^{\circ} \mathrm{C}$. The proteins were purified under native conditions using Ni-NTA-agarose columns (Invitrogen; Probond Purification System; \#K850-01), or on glutathione-Sepharose 4B columns (Amersham Biosciences; \#27-4570) previously equilibrated with 30 bed volumes of: $50 \mathrm{mM}$ Tris- $\mathrm{HCl}$ (pH 8), $1 \mathrm{mM}$ EDTA, $150 \mathrm{mM} \mathrm{NaCl}, 0.5 \%$ Tween-20, and 1\% Triton X-100. The retained fusion proteins were cleaved on the column by using the ProTEV protease (Promega; \#V605A), collected, and concentrated in a centrifugal filter device (10000 nominal molecular weight limit; Amicon Microcon YM-10 \#42407; Millipore). The TEV protease was removed by immobilization on affinity resins (Amersham Biosciences; \#17-0575-01).

\section{Evaluation of MOR-NMDAR1 Interactions}

The interaction of the NR1 C-terminal sequence $\mathrm{C} 0-\mathrm{C} 1-\mathrm{C} 2$ $(100 \mathrm{nM})$ or its clipped $\mathrm{C} 0-\mathrm{C} 2$ sequence $(100 \mathrm{nM})$ with $\mathrm{C}-$ terminus MOR1 or MOR1C variants $(100 \mathrm{nM})$ was studied. The NR1 proteins were incubated with $100 \mathrm{nM}$ GST protein (GenScript, USA; Z02039. negative control) or with GSTMOR sequences in $450 \mu$ of HBS-EP buffer (10 mM HEPES (pH 7.4), $150 \mathrm{mM} \mathrm{NaCl}, 3 \mathrm{mM}$ EDTA, $0.005 \%$ P20) and mixed by rotation for $30 \mathrm{~min}$ at room temperature. After the incubation, glutathione-Sepharose was added to these protein mixtures. The pellets obtained by centrifugation were washed three times and solubilized in $2 \times$ Laemmli buffer. The presence of NR1 C-terminal sequences was analyzed by western blotting using an antibody against the C2 segment (NMDAR1 C2, 1:500, ab6485).

Phosphorylation of the NR1 subunit of the NMDAR $(\mathrm{C} 0-\mathrm{C} 1-\mathrm{C} 2,100 \mathrm{nM})$ was performed in a $50-\mu \mathrm{l}$ reaction mixture containing $60 \mathrm{mM}$ NaHEPES ( $\mathrm{pH} 7.5$ ), $3 \mathrm{mM} \mathrm{MgCl}$, $3 \mathrm{mM} \mathrm{MnCl} 2,3 \mu \mathrm{M}$ Na-orthovanadate, $1 \mathrm{mM} \mathrm{DTT}$, and $250 \mu \mathrm{M}$ ATP. The reaction was performed at room temperature in the presence of $30 \mathrm{nM}$ protein kinase- $\mathrm{C} \gamma$ $(\mathrm{PKC} \gamma)$, and it was terminated after $20 \mathrm{~min}$ by the addition of the PKC inhibitor Gö7874 (Calbiochem; \#365252) at a concentration of $5 \mu \mathrm{M}$. The influence of PKC phosphorylation of NR1 C0-C1-C2 on its binding to the MOR was then determined as described above.

\section{SPR Analysis}

Interactions were determined by using a BIACORE X (GE Healthcare). NR1 C-terminal sequences $\mathrm{C} 0-\mathrm{C} 1-\mathrm{C} 2$ or $\mathrm{C} 0-$ C2 $(50 \mu \mathrm{g} / \mathrm{ml})$ were coupled to Channel-2 of CM5 sensor chips (GE; BR-1000-14) by amine coupling at pH 7.0 (GE; BR-1000-50); Channel-1 acted as the blank. The sensor surface was equilibrated with HBS-EP buffer (GE; BR-100188). After passing the MOR1 C-terminal sequence $(75 \mu \mathrm{l})$ over the sensor surface, the sensorgrams were collected at $25{ }^{\circ} \mathrm{C}$ with a flow rate of $5 \mu \mathrm{l} / \mathrm{min}$. The CM5 sensor chip was regenerated after each cycle with two $15-\mu \mathrm{l}$ pulses of $10 \mathrm{mM}$ glycine given at a 30-s interval ( $\mathrm{pH} 2.5$; GE; BR-100356). Increasing analyte concentrations were studied, and the results were plotted by using the BIAevaluation software (v 4.1).

\section{Cell Culture and Transfection}

Chinese hamster ovary ( $\mathrm{CHO})$ cells were grown in Dulbecco's modified Eagle's medium (DMEM) supplemented with $1 \mathrm{mM}$ sodium pyruvate, $2 \mathrm{mM}$ L-glutamine, $100 \mathrm{U} /$ $\mathrm{ml}$ streptomycin, $100 \mu \mathrm{g} / \mathrm{ml}$ penicillin, and $10 \%(\mathrm{v} / \mathrm{v})$ fetal bovine serum at $37{ }^{\circ} \mathrm{C}$ and in an atmosphere of $5 \% \mathrm{CO}_{2}$. The cells were transfected for $48 \mathrm{~h}$ at $\sim 70 \%$ confluence by using Lipofectamine 2000 (Invitrogen) according to the protocol of the manufacturer. The cells were further incubated for 18-36 $\mathrm{h}$ prior to testing for transgenic expression.

\section{BiFC Analysis}

The plasmid pPD49.83 was used to generate two cloning vectors for Bimolecular Fluorescence Complementation (BiFC) analysis. The constructs containing the heat-shock promoter, hsp-16.41, an Myc or hemagglutinin tag for detection of BiFC fusion proteins, a multiple cloning site for sub-cloning the gene of interest, a linker sequence, and the $\mathrm{N}$-terminal fragment of Venus truncated at residue 173 (VN173) or the C-terminal fragment of Venus starting at residue 155 (VC155) were a gift from Dr Chang-Deng Hu at Purdue University (USA). Full-length murine NR1 (CO-C1$\mathrm{C2}$ ) and MOR were sub-cloned in-frame into the pCE-BiFCVN173 or pCE-BiFC-VC155 plasmid by using standard cloning strategies. Fragments were amplified by PCR using the following primers: NR1: $5^{\prime}$-AGGA/AGCTTAGCACCATG CACCTGCTGACATTC-3' (forward)/ $/ 5^{\prime}$-CGT/CTAGAGCGT CTCTGCTCTCCCTATGAC-3' (reverse) for the pCE-BiFCVN173 and MOR 5'-CCGG/TCGACGCAAGCATTCAGAAC CAAGGACA-3' (forward) $/ \overline{5}^{\prime}$-GGTAC/CGGATGGCGTGGGA CCCAGTTTG-3 (reverse) for pCE-BiFC-VC155 plasmid. Samples were imaged on glass-bottom plates (MatTek, USA) by confocal microscopy by using a Leica DMIII 6000 CS confocal fluorescence microscope equipped with a TCS SP5 scanning laser.

\section{Animals, Icv Injection, and Evaluation of Antinociception}

Male albino CD-1 mice weighing $22-25 \mathrm{~g}$ were used. The response of the animals to nociceptive stimuli was determined by the warm water $\left(52^{\circ} \mathrm{C}\right)$ tail-flick test. Baseline latencies ranged from 1.5 to $2.2 \mathrm{~s}$, and they were not significantly affected by the kinase inhibitors used or their solvent. A cut-off time of $10 \mathrm{~s}$ was used to minimize the risk of tissue damage. Antinociception was expressed as a percentage of the maximum possible effect $(\mathrm{MPE}=100 \times$ (test latency-baseline latency)/(cut-off time-baseline latency)). The animals were lightly anaesthetized with ether and morphine sulphate (Merck, Darmstadt, Germany). Then, 15 and 180 pmol NMDA (Tocris; \#0114), $1 \mathrm{nmol}$ Gö7874 (Calbiochem; \#365252), 15 nmol KN93 (Calbiochem; \#422711), 5 and $15 \mathrm{nmol}$ PKA inhibitor 6-22 amide (Sigma-Aldrich; \#P6062), or 20 and $100 \mathrm{nmol} \beta$ ARK1 inhibitor (Calbiochem; \#182200) were injected in a volume of $4 \mu \mathrm{l}$ into the lateral ventricle. Saline was likewise administered as a control. Antinociception was assessed at different time intervals thereafter.

The development of morphine-induced acute opioid tolerance was monitored $24 \mathrm{~h}$ after giving a priming dose 
of $10 \mathrm{nmol}$ morphine intracerebroventricularly. Thus, a dose-effect curve of morphine was constructed by determining analgesia $30 \mathrm{~min}$ after the injection of the opioid. This interval corresponds to morphine analgesic peak effect.

\section{Statistical Significance}

ANOVA followed by the Student-Newman-Keuls test (SigmaStat; SPSS Science Software, Erkrath, Germany) was performed and significance was defined as $P<0.05$.

\section{RESULTS}

\section{MOR and NMDAR Associate in Mouse Neuronal Tissue}

NMDARs, which control a cation channel that is highly permeable to $\mathrm{Ca}^{2+}$, are formed by a tetramer consisting of a pair of NR1 subunits associated with at least one type of NR2 (A, B, C, and D) or NR3 (A and B) subunit (Mori and Mishina, 1995). To determine the existence of an association between MORs and NMDARs, we first analyzed whether they could be co-immunoprecipitated from mouse brain synaptosomes. In neuronal membranes, the cytosolic regions of these two receptors interact with third partner proteins; thus, in the immunoprecipitation analysis, we used antibodies directed to the extracellular domains of the MOR and NR1 subunits. Because MOR variants show differences in their cytosolic C-terminus (Pan, 2005), our approach would not distinguish among them. The MOR coprecipitated with NR1 subunits but showed little or no coprecipitation with NR2/3 subunits. This pattern was observed in the PAG, cerebral cortex, striatum, and dorsal spinal cord, but co-precipitation was almost absent from the cerebellum (Figure 1a). Using an antibody against the NR1 extracellular peptide sequence, we determined that the NR1 subunit co-precipitated with MOR1 and MOR1C variants (Figure 1b). NR1 subunits show variability in their distal Cterminus and are classified as C2 and C2' (Zukin and Bennett, 1995). The C-terminus of the NR1 subunit is composed of $\mathrm{C} 0-\mathrm{C} 1-\mathrm{C} 2\left(\mathrm{C}^{\prime}\right)$ regions, variants $011 / 111$ and 010/110 respectively; however, some NR1 lack the C1 segment, $\mathrm{C} 0-\mathrm{C} 2\left(\mathrm{C2}^{\prime}\right)$, variants $001 / 101$ and $000 / 100$ respectively. An ex vivo analysis of the NR1 subunits co-precipitated with the MORs indicated the presence of both $\mathrm{C} 2$ and $\mathrm{C} 2{ }^{\prime}$ variants (Figure 1c).

The MOR-NR1 association withstood solubilization by sonication-Nonidet-p40 or RIPA buffer (Pierce; 89900), although it was destroyed by $1 \%$ SDS solubilization buffer. Because SDS at this concentration prevents interactions between proteins, the presence of the ionic detergent was reduced with octylthioglucoside. The anti-MOR antibody subsequently captured the MOR without the associated NR1 subunit (Figure 2a). This observation suggests that the MOR associates (directly or indirectly) with the NR1 subunit in the synaptic membrane, and when separated the mutual affinity shown by these two proteins is probably occluded by the presence of third partner proteins. Therefore, MORNR1 co-precipitation is not a result of their interaction during the solubilization procedure, and certainly suggests a functional role for this relationship.

Given the MOR-NR1 association in synaptosomal membranes, we next addressed whether these receptors a

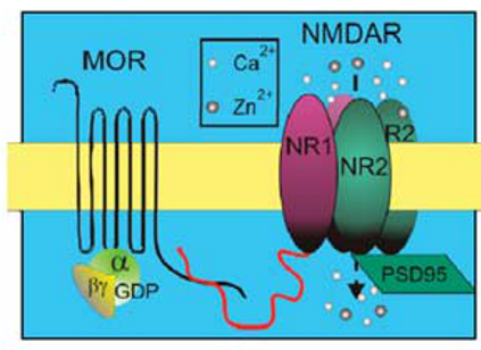

IP: MOR (PAG)

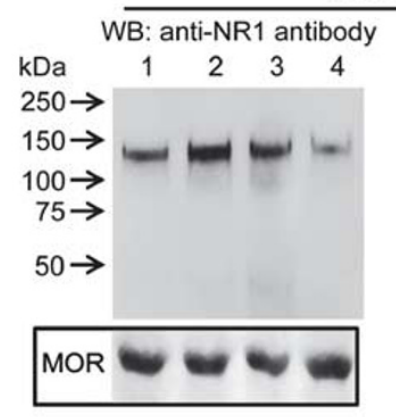

IP: MOR

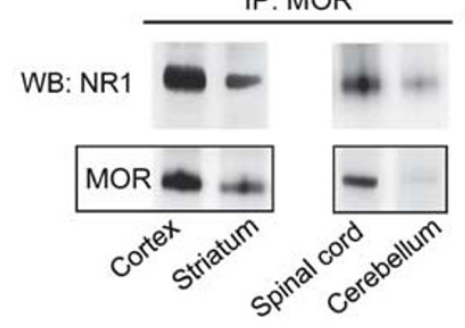

b $\underline{\text { PP: NMDAR1 (PAG) }}$

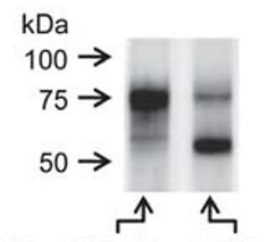

WB: MOR1C MOR1

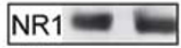

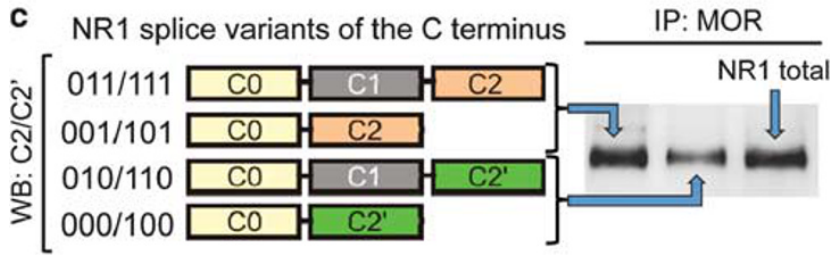

Figure I MORI and NMDAR associate in the nervous system. Reciprocal co-precipitation of MOR and NRI subunits from various areas of mouse CNS system tissue. (a) Solubilized synaptosomes were incubated with biotinylated $\lg$ G directed to the second extracellular loop of the MOR (2EL). After being recovered with streptavidin-sepharose, the MORcontaining complexes were processed to remove the IgG before immunodetection of MORI and associated proteins (see section Materials and methods). For the PAG assay, the anti-NRI antibodies used were the following: Lane- I, Abcam ab I880; lane-2, Abcam ab28669; lane-3, SigmaGenosys (482-456); lane-4, Abnova PABI222I. The antibodies used for detection of PAG NR subunits were as follows: NRI, Abcam abl880; NR2A, Abcam ab 14596; NR2B, Abcam ab I4400; NR2C, Abcam abl I0; and NR3AB, Abcam ab2639. The Abcam abl880 antibody was used to detect MOR-associated NRI derived from the other structures. (b) The Sigma-Genosys (482-456) antibody directed against the NRI extracellular peptide sequence co-precipitated MORI (MOR CT antibody) and MORIC (Neuromics; \#RA2000I) variants. (c) To determine the NRI variants associated with the MOR membrane, proteins were solubilized and the MOR was immunoprecipitated (IP) with affinity-purified IgG anti-MOR (2EL). The NRI subunits that co-precipitated with MORs were recognized with antibodies directed to the NMDARI (ab I880), NMDARI C2 (ab6485), and NMDARI C2' (ab6486) regions of the NRI subunit C-terminus.

physically interact in living cells. The BiFC approach is used for the detection of protein direct interactions in the normal cellular environment (Shyu et al, 2008). Thus, CHO cells 
a

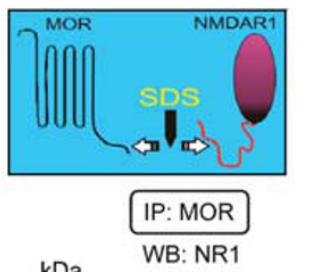

$\mathrm{kDa}$

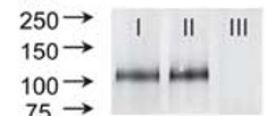

$75 \rightarrow$

WB: MOR

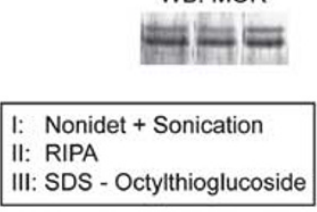

C
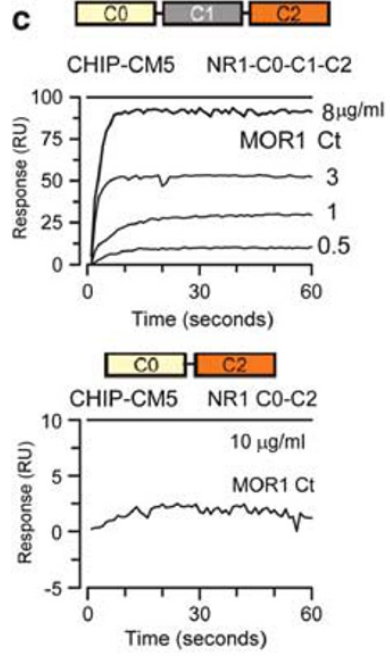

Figure 2 Direct physical interaction of MORs with NMDARs: involvement of the $C$ terminal sequences. (a) The membranes were solubilized and the MOR was then immunoprecipitated (MOR 2EL antibody) to study the association between MOR and NRI (MOR CT and abl880 antibodies). Further details are provided under section Materials and methods. (b) BiFC analysis of the interaction between MORI and NRI. $\mathrm{CHO}$ cells were transiently co-transfected with cDNAs encoding $\mathrm{NRI}^{\mathrm{VNI}}{ }^{33}$ and MORI ${ }^{\mathrm{VCI}} 55(0.3 \mu \mathrm{g})$. The confocal fluorescent signals are obtained when two molecules of NRI ${ }^{\mathrm{VN}}{ }^{773}$ and MORI VCI55 associate. Left: Phase field and fluorescent images are combined. Right: Fluorescent image of positive cells in the field. (c) SPR analysis of the MOR-NRI interaction. The MORI C-terminal sequence (287-399) interacts with the NRI C-terminus containing the $\mathrm{Cl}$ region. The sensorgrams were constructed with MORI Ct in the fluid phase at the concentrations $(\mu \mathrm{g} / \mathrm{ml})$ indicated. The NRI CO-C2 produced no signal with the MORI C-terminus. (d) In vitro pull-down assays. NRI C0-Cl-C2 or NRI C0-C2 C-terminus variants were incubated with either the GST-MORIC Cterminus (337-439) (lane-I) or the GST-MORI C-terminus (287-399) (lane-2). Both MORI C-terminal sequences bind to and co-precipitate with NRI CO-Cl-C2 but not NRI CO-C2. GST did not bind to the NRI Cl region (lane-3). P, captured and precipitated with glutathione-Sepharose; WB, anti-GST or anti-NRI C2 region antibody.

were transfected with a mix $(1: 1)$ of plasmids expressing MOR1 coupled to VC155 and NR1 (C0-C1-C2) coupled to VN173 at the corresponding C-termini. The physical interaction of the carrier proteins allows the VC155 and VN173 fragments to couple and form a stable fluorescent complex. Numerous cells showed the fluorescent signal, indicating that MOR and NR1 can form a heterodimer in vivo (Figure $2 \mathrm{~b}$ ). Because these $\mathrm{VC}$ and $\mathrm{VN}$ fragments are not fluorescent on their own, the cells that did not fluoresce were likely not transfected or were singly transfected with either the MOR1-VC155 or the NR1-VN173 construct.

Dopamine-D1 receptors and group-I metabotropic glutamate receptor-5a (mGlu5a) form complexes with NR1 subunits through their respective C-termini (Fiorentini et al, 2003; Perroy et al, 2008). Accordingly, we determined the role of these protein regions in the interaction between MOR and NR1 (Supplementary Figure 1). Using surface plasmon resonance (SPR) analysis, which detects protein interactions during co-incubation, we observed a robust interaction between the MOR1 C-terminus and the $\mathrm{C} 1$ region of the NR1 C-terminus (Figure 2c). In vitro coincubation assays confirmed this pattern; the MOR1 and the MOR1C C-termini bound to the NR1 cytosolic sequence $\mathrm{C} 0-\mathrm{C} 1-\mathrm{C} 2$ but not NR1 C0-C2 (Figure 2d). Ser residues in the C1 sequence, that is, Ser890, Ser896, and Ser897, are implicated in the regulation of NMDAR function by PKC and PKA (Hisatsune et al, 1997; Tingley et al, 1997). The MOR1-NR1 direct binding was greatly diminished by the action of $\mathrm{PKC} \gamma$ on this critical $\mathrm{C} 1$ domain (Figure 3 ). The analysis of the NR1 C-terminal sequence, C0-C1-C2 (DNASTAR; Protean v8.0.2), revealed a cluster of positively charged residues at the end of the C1 segment (889-898: SSFKRRRSSK) that could interact with the negative regions in the C-terminus of MOR1 and MOR1C. Phosphorylation of these NR1 C1 Ser residues reduces the positive charge, thereby weakening the association between MOR and NMDAR1. The isoelectric point shifts from 11.72-9.98 (P), 7.61 (P-P), and 6.8 (P-P-P) (ExPASy's Compute pI/Mw).

\section{Pharmacological Recovery of Opioid Analgesia from Tolerance}

Intracerebroventricular (icv) administration of morphine to mice produces a dose-dependent antinociceptive effect that reaches a maximum at about $30 \mathrm{~min}$ after injection. The administration of a 10 -nmol dose brings about a profound decrease in the response to successive doses of morphine that is a result of acute analgesic tolerance. The lower 3-nmol dose produces no single-dose tolerance, indicating that the effects of morphine have to reach a certain threshold before desensitization is achieved (RodríguezMuñoz et al, 2007a). This single-dose (acute) tolerance can be detected $3 \mathrm{~h}$ after administration, but is clearly observed when the analgesic dose-response curve is assessed $6 \mathrm{~h}$ after the animals receive the initial priming dose of $10 \mathrm{nmol}$ morphine. Therefore, this process requires time to develop (Rodríguez-Muñoz et al, 2007b). In our assay, the apparent $\mathrm{ED}_{50}$ of icv morphine was $3.75 \mathrm{nmol}$ per mouse $(95 \%$ confidence limits: 2.85-4.90) for the control mice and $>10 \mathrm{nmol}$ per mouse for mice pre-treated $(24 \mathrm{~h})$ with 10 nmol morphine. We then determined whether inhibition of the Ser and Thr kinases PKC, PKA, and G-protein receptor kinase-2 (GRK2), could restore morphine analgesic potency from the acute tolerant state. The mice received the priming dose of $10 \mathrm{nmol}$ morphine. Twenty-four hours later, they were injected intracerebroventricularly with the PKA inhibitor 6-22 amide at 5 or $15 \mathrm{nmol}$, the PKC inhibitor 


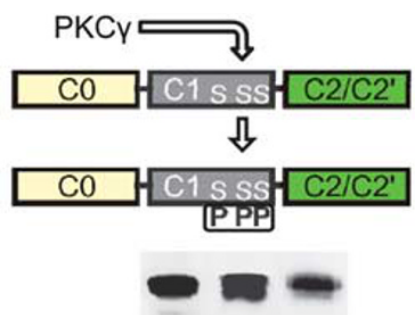

WB: P-Ser 890896897
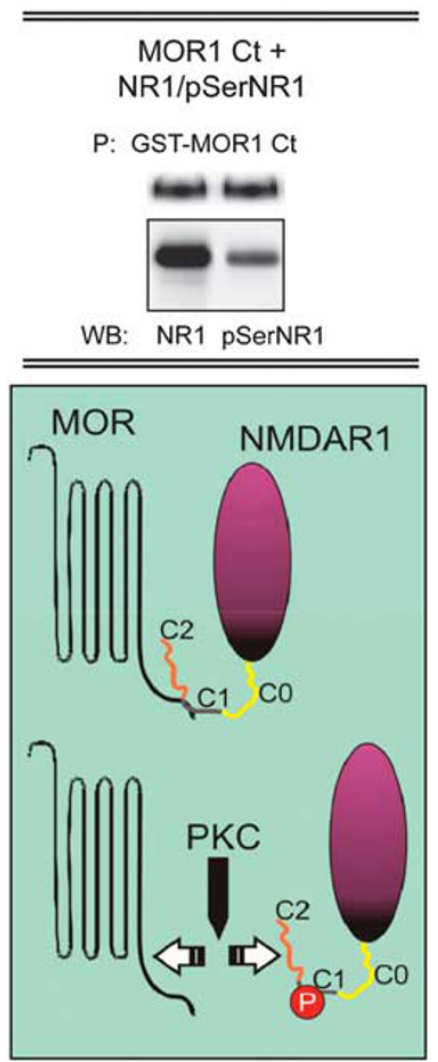

Figure 3 Influence of PKC on the association of MORI and NRI Ctermini. The $\mathrm{NRI} \mathrm{CO}-\mathrm{Cl}-\mathrm{C} 2$ sequence $(100 \mathrm{nM})$ was exposed to $\mathrm{PKC} \gamma$ activity $(30 \mathrm{nM})$. Western blot (WB) analysis revealed phosphorylation of Ser 890, Ser896, and Ser897 located in the NRI Cl segment. The GST-MORI C-terminus ( $100 \mathrm{nM}$ ) was then incubated with $100 \mathrm{nM}$ NRI $\mathrm{CO}-\mathrm{Cl}-\mathrm{C} 2$ that had or had not been exposed to active $\mathrm{PKC} \gamma$. The GST-MORI Ct was then precipitated (P) with glutathione-Sepharose and the associated NRI was evaluated by WB by using the anti-NRI C2 antibody.

Gö7874 at $1 \mathrm{nmol}$, and ,the GRK2 inhibitor i $\beta$ ARK1 at 20 or $100 \mathrm{nmol}$. The effect of increasing opioid test doses was assessed $30 \mathrm{~min}$ after the inhibitor injection. The dose of $20 \mathrm{nmol}$ i $\beta$ ARK1 reverses antinociceptive tolerance in DAMGO-tolerant mice. However, doses up to $100 \mathrm{i} \beta$ ARK1 fail in recovering morphine from antinociceptive tolerance (Sánchez-Blázquez et al, 2008; Hull et al, 2010). On the other hand, the PKA inhibitor $6-22$ amide at $5 \mathrm{nmol}$ is effective in restoring morphine analgesia from NMDA antagonism (Figure 7a). Therefore, given the suitability of the doses used for the kinase inhibitors, we concluded that tolerant mice recovered their responses to morphine after PKC inhibition but not after PKA or GRK2 inhibition (Figure 4a).

\section{Effect of Morphine on the Association between MOR and NR1: Role of PKC}

For those cases in which receptor dimerization has been proposed, the formation of the complex usually affects the properties of each individual partner, particularly the capacity of agonists to promote receptor internalization. Therefore, we first determined the effect of in vivo administration of morphine on the stability of the PAG MOR-NMDAR association when analyzed ex vivo. In agreement with previous reports (reviewed by RodríguezMuñoz et al, 2007b), a single icv dose of $10 \mathrm{nmol}$ morphine promoted no significant changes in cell-surface MORs. At the intervals at which morphine analgesia declined, but not before, the association of NR1 subunits with the MOR diminished (Figure 4b). The NR1 subunits associated with MORs showed no Ser phosphorylation, but in the membrane morphine increased the activating phosphorylation of NR1 Ser890 and NR2A tyrosine-1325, as well as CaMKII autophosphorylation at Thr286 (Figure 4c). Morphine also diminished the association of the MOR with the postsynaptic marker PSD95 (Figure 5a). These changes were accompanied by increases in MOR phosphorylation, decreases in MOR coupling to the regulated G-proteins (Figure 5b), and the onset of acute tolerance (RodríguezMuñoz et al, 2007b). A second dose of $10 \mathrm{nmol}$ morphine given $24 \mathrm{~h}$ after the priming dose produced only weak analgesic effects, indicating that acute tolerance had developed (Figure 4). Under these circumstances, morphine further reduced the number of MOR-NR1 complexes (Figure $5 b$ ). All these molecular changes brought about by the icv dose of $10 \mathrm{nmol}$ morphine were prevented by the co-administration of the MOR-selective antagonist $\mathrm{Cys}^{2}$, $\mathrm{Tyr}^{3}, \mathrm{Orn}^{5}, \mathrm{Pen}^{7}$-amide (CTOP; $0.6 \mathrm{nmol}$ per mouse) (Gulya et al, 1988) (Supplementary Figure 2).

Inhibition of PKC before the administration of this priming dose of morphine prevented the Ser phosphorylation of the MOR, and, consequently, the receptor maintained its control over G-protein-mediated transduction. In these circumstances, morphine did not diminish the MORNR1 association, and no analgesic tolerance developed (Figures 4 and 6a). In mice that had been rendered tolerant to morphine, administration of Gö7874 restored MOR function and morphine regained its analgesic potency within a few minutes. This positive effect was related to a series of molecular changes, such as reformation of MORNR1 complexes, dephosphorylation of MORs, and recovery of MOR regulation over G-proteins. Thus, the mice showed a full analgesic response to the second dose of morphine, but without separation of Gö7874-reformed MOR-NR1 complexes or internalization of MORs (Figure 6b). Therefore, morphine-induced analgesic acute tolerance is mostly mediated by PKC activity on a series of signaling proteins. Inhibition of this kinase resets the system to the parameters observed before the administration of the morphine priming dose and prevents the opioid from inducing changes related to MOR desensitization.

We previously reported that i $\beta$ ARK1, a GRK2 inhibitor, does not affect the development of morphine tolerance (Sánchez-Blázquez et al, 2008). We have now determined that GRK2 inhibition did not prevent morphine from inducing MOR-NR1 separation. Moreover, i $\beta$ ARK1 did not 
reverse analgesic tolerance or promote MOR-NR1 reassociation (Figures 4 and 6c). Similarly, inhibition of PKA did not rescue morphine tolerance or stimulate the regrouping of MOR with the NR1 subunit.

\section{NMDAR Activation Reduces Morphine Analgesia and Disrupts MOR-NR1 Association by a PKA-Dependent Mechanism}

The icv administration of NMDA, an agonist that acts at the glutamate-binding site on the NR2 subunit, resulted in the loss of the capacity of morphine to produce antinociception (Figure 7a). The NMDAR inhibitors MK801 (Tocris; \#0924) (Wong et al, 1986) and D-AP5 (Tocris; \#0106) (Olverman et al, 1984) injected intracerebroventricularly at $0.3 \mathrm{nmol}$ $10 \mathrm{~min}$ before NMDA preserved morphine analgesia effects. Inhibition of PKC (1 nmol Gö7874) or GRK2 (100 nmol $\mathrm{i} \beta \mathrm{ARK} 1)$ did not alter the negative effect of NMDA on

a
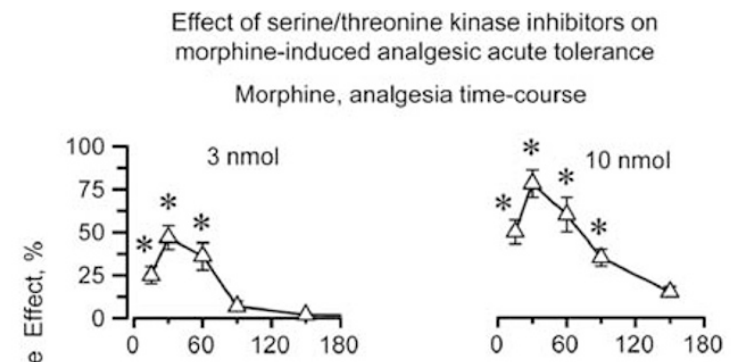

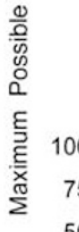

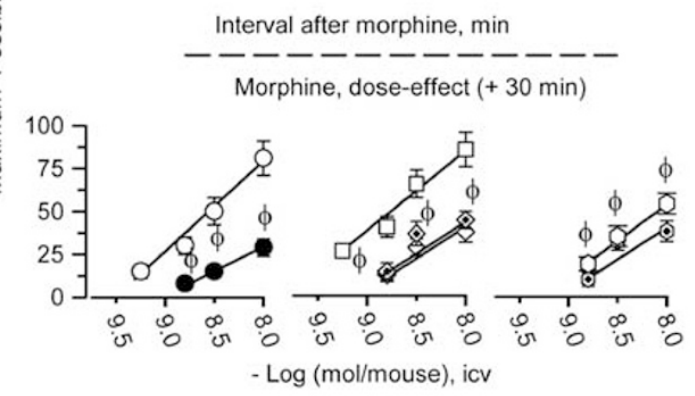

O Morphine dose-effect ( $M$ d-e)

- Morphine (10 nmol) -24 h- (M d-e)

․ Morphine -24 h- [1 nmol Gö7874-30 m- (M d-e)]

$\diamond$ Morphine -24 h- [5 nmol PKA inhibitor 6-22 amide -30 m- (M d-e)]

- Morphine -24 h- [15 nmol PKA inhibitor 6-22 amide -30 m- (M d-e)]

- Morphine -24 h- [20 nmol ißARK1 -30 m- (M d-e)]

o Morphine -24 h- [100 nmol ißARK1 -30 m- (M d-e)]

b

\section{NR1-associated MOR: effect of morphine}

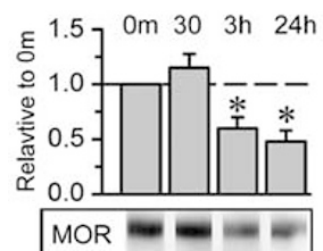

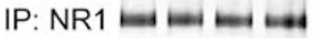

$$
\text { C Membrane }
$$

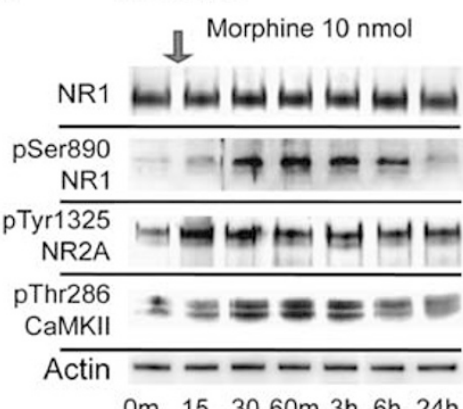

morphine analgesia. Moreover, the inhibitor of CaMKII activity, KN93 (Calbiochem; \#422711), used at $15 \mathrm{nmol}$, dose that prevents morphine acute tolerance (Sánchez-Blázquez et al, 2008; Garzón et al, 2011), also failed against the antagonism of NMDA on morphine analgesia. However, in mice treated with the PKA inhibitor, NMDA did not alter morphine normal analgesic effect. Although NMDA did not promote a substantial reduction of MOR or NR1 subunits in the PAG synaptosomal preparation, it greatly increased the Ser phosphorylation of the MOR and the uncoupling of the MOR from the regulated G-proteins. These desensitizing changes were accompanied by reductions in MOR-NR1 coprecipitation (Figure $7 \mathrm{~b}$ ). The direct effect of NMDA on the NMDAR promoted some activating autophosphorylation of CaMKII, although it hardly affected PKC-mediated Ser phosphorylation of the NR1 subunit or Src-mediated tyrosine phosphorylation of NR2A/B (Figure 7c). These NMDA-induced changes on MOR and NMDAR signaling were all prevented by the NMDAR antagonists MK801 (Supplementary Figure 3) or D-AP5 (not shown). The inhibition of GRK2, CaMKII, or PKC did not modify the NMDA-induced MOR-NR1 disruption. On the contrary, inhibition of PKA preserved the MOR-NR1 association (Figure 7d).
Figure 4 Effect of PKC, PKA, and GRK2 inhibition on morphine-induced acute analgesic tolerance. (a) Mice were intracerebroventricularly injected with 3 or $10 \mathrm{nmol}$ morphine and antinociception was assessed by the warm water $\left(52^{\circ} \mathrm{C}\right)$ tail-flick test. Each point is the mean \pm SEM from groups of eight mice. The administration of a priming dose of $10 \mathrm{nmol}$, but not $3 \mathrm{nmol}$, morphine promoted acute analgesic tolerance. This was demonstrated by constructing a dose-effect curve for morphine $24 \mathrm{~h}$ after the mice received the priming dose. The pharmacological rescue from morphine-induced single-dose tolerance was studied. The PKC inhibitor Gö7874 (I nmol), the PKA inhibitor 6-22 amide ( 5 and $15 \mathrm{nmol}$ ), and the GRK2 inhibitor i $\beta$ ARKI (20 and $100 \mathrm{nmol}$ ) were injected intracerebroventricularly $30 \mathrm{~min}$ before constructing the morphine dose-effect curve. * Significantly different from the basal latencies obtained before the icv morphine injection. ${ }^{\phi}$ Significantly different from the value obtained in the absence of the priming dose of morphine (ANOVA-Student-NewmanKeuls test; $p<0.05)$. (b) Morphine $(10 \mathrm{nmol}$ per mouse) reduced the association of NRI subunits with MORs. The NRI subunits were immunoprecipitated (IP) with the anti-NRI antibody (ab|880) and the associated MORs were then evaluated by western blotting (anti-MOR CT). Representative blots are shown. NRI was used as a loading control. The immunosignals (average optical density of the pixels within the object area/ $\mathrm{mm}^{2}$; Quantity One Software, Bio-Rad) were expressed relative to the levels of MORs observed in control mice that had not received morphine (given an arbitrary value of I). Each data point represents the mean of three assays performed on PAG samples obtained from independent groups of mice. The data are presented as the mean \pm SEM (Sigmaplot $\mathrm{v}$ I I). *Significantly different from the value of $0 \mathrm{~m}$ (controls that did not receive morphine) (ANOVA-Student-Newman-Keuls test; $p<0.05$ ). (c) Phosphorylations related to NMDAR-CaMKII activity were studied in the PAG membranes obtained from morphine-treated mice. The mice were administered $10 \mathrm{nmol}$ morphine intracerebroventricularly. The animals were then divided into groups of six mice and killed at the postopioid intervals indicated. The presence of NRI and activating phosphorylations of NRI, NR2A, and CaMKII was determined in the PAG synaptosomal membrane. The assay was repeated three times on samples derived from different groups of mice and the results were comparable. 


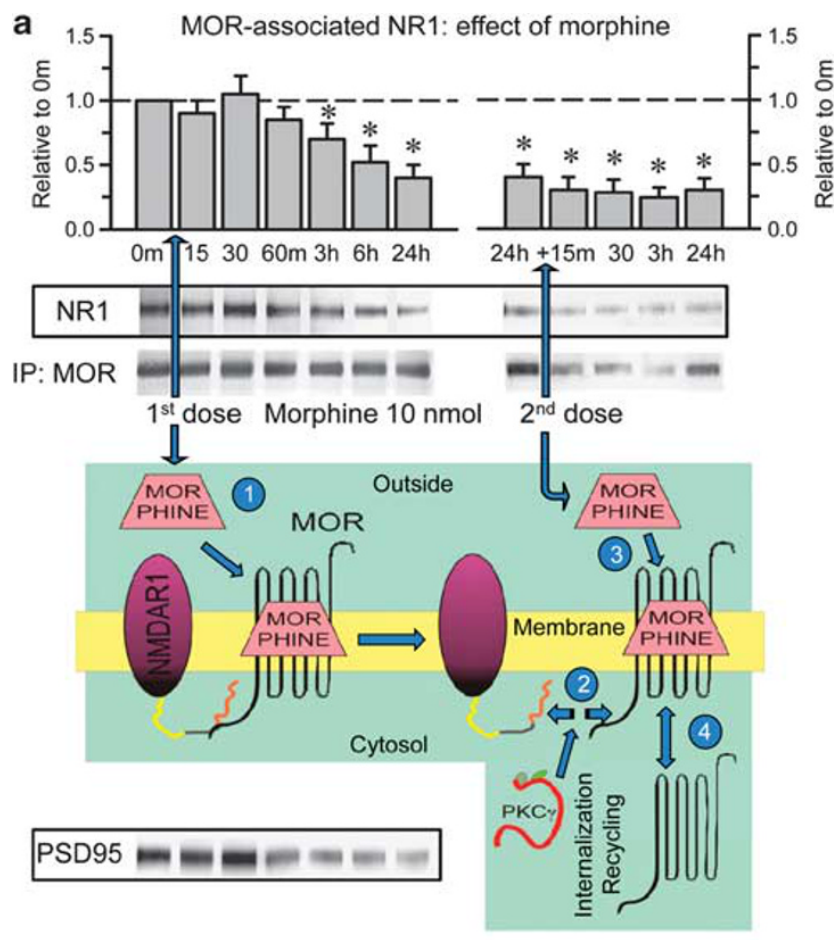

b

\begin{tabular}{|c|c|c|}
\hline $\mathrm{IP}: \mathrm{MOR}$ & $\begin{array}{l}1^{\text {st }} \text { dose Morphine } 10 \mathrm{nmol} \\
\mathbb{\Downarrow}\end{array}$ & $2^{\text {nd dose }}$ \\
\hline $\begin{array}{l}\text { P-Ser } \\
\text { MOR }\end{array}$ & $4+4606=$ & 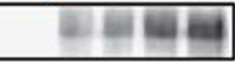 \\
\hline Gai2 & - & $=----$ \\
\hline
\end{tabular}

Figure 5 Effect of repeated morphine administration on MORassociated proteins. Groups of mice received an initial icv dose of $10 \mathrm{nmol}$ morphine. They then received a second dose of $10 \mathrm{nmol}$ morphine or saline $24 \mathrm{~h}$ later. The mice were then killed at the indicated time points. For each interval studied, the PAG structures from six mice were pooled for the ex vivo determinations. (a, b) The MOR was immunoprecipitated (IP) with the 2EL antibody and the associated NRI, PSD95, and Goi2 proteins were evaluated. The MOR Ser phosphorylation status was determined with the IC8 clone after applying denaturing conditions to remove associated proteins that could mask the findings (see section Materials and methods). *Significantly different from the value of $0 \mathrm{~m}$ (controls that did not receive morphine). Details are as in Figure 4b.

\section{DISCUSSION}

We have observed that metabotropic MORs and glutamatedriven ionotropic NMDARs are associated in different areas of the mouse CNS and that PKC and PKA regulate their relation. During recent years, different laboratories have convincingly described the functional cross-regulation of MORs and NMDARs in pain control. Moreover, anatomical studies, ultrastructural analyses, and electrophysiological data have suggested that the opposing interaction of MORs and NMDARs could be achieved in the same neuron within a common cellular compartment. Although it is complicated to ascertain the direct physical association of these two receptors in in vivo studies we have, however, provided ex vivo and in vitro data demonstrating that such an

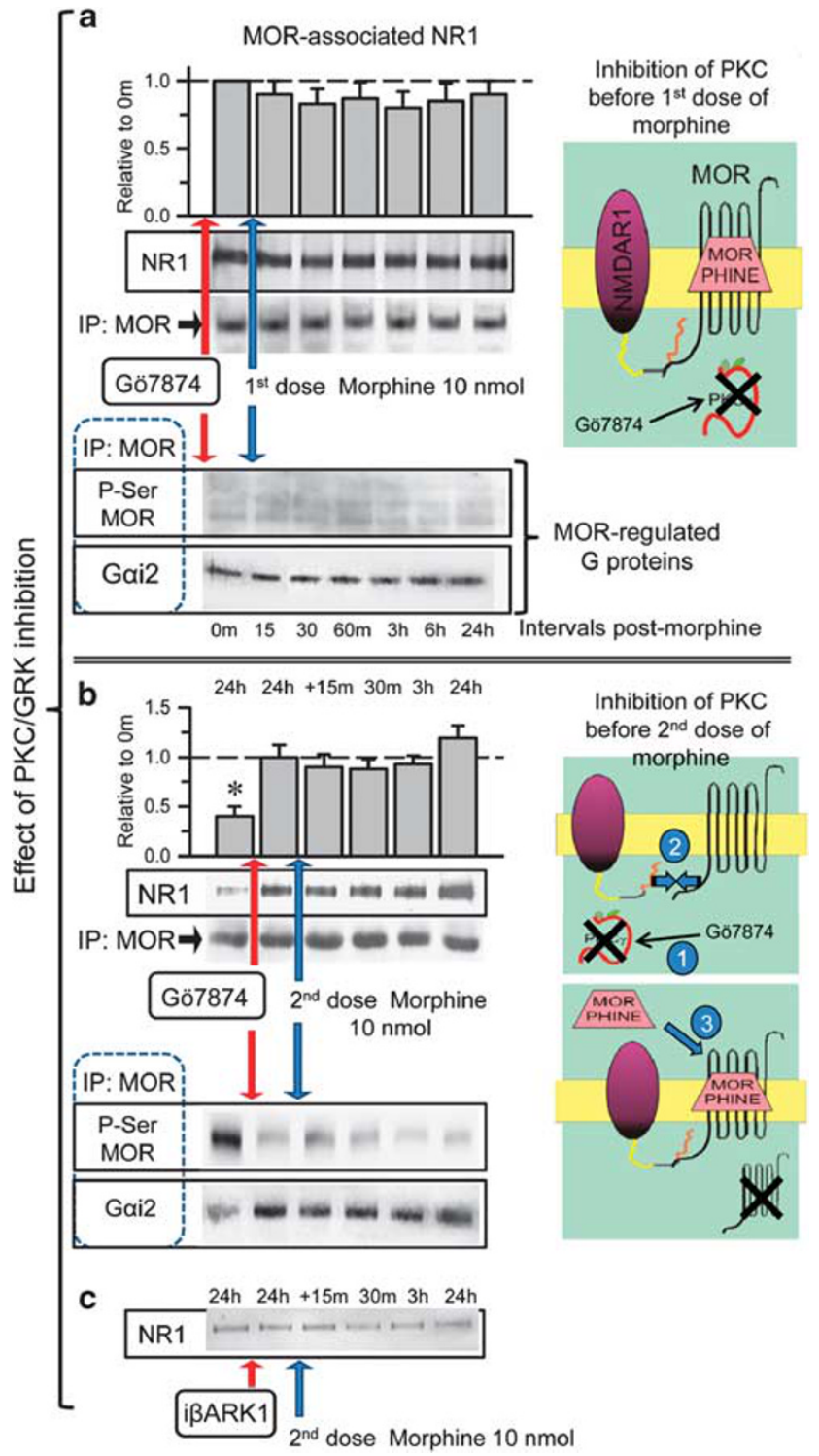

Figure 6 Morphine promotes MOR-NRI separation by a PKCmediated mechanism. (a) The PKC inhibitor Gö7874 (I nmol) was injected intracerebroventricularly to mice 30 min before the administration of $10 \mathrm{nmol}$ morphine. At the intervals indicated, groups of six mice each were killed and the PAG was obtained for the ex vivo analysis. MOR was immunoprecipitated (IP) to determine its Ser phosphorylation and association with NRI and Gai2 subunits. (b) Mice that had received a priming dose of $10 \mathrm{nmol}$ icv morphine were injected with I nmol icv Gö7874 24h later. After 30 min, the mice received a second test dose of $10 \mathrm{nmol}$ icv morphine. *Significantly different from the value of $0 \mathrm{~m}$ (controls that did not receive morphine; Figure 7a). Details are as in panel a. (c) Using the protocol in panel b, the mice were injected with $100 \mathrm{nmol}$ icv i $\beta$ ARKI 30 min before the morphine test dose. Further details are provided under section Materials and methods and the legend to Figure 5.

interaction is certainly possible. Notwithstanding, just the finding of the association between MORs and NMDARs is of relevance to the pharmacology of pain, particularly to the clinical management of opioid-resistant neuropathic pain. At the molecular level, various signaling proteins have been implicated in the bidirectional MOR-NMDAR regulation (Trujillo, 2002; Garzón et al, 2008). In the framework of this MOR-NMDAR association, without 
ruling out the possibility of their physical interaction, those regulatory mechanisms have increased importance and provide the rationale to identify markers associated with increased nociception or therapeutic targets to control these dysfunctions.

The ex vivo analyses provided little information on the precise NR2/3 composition of MOR-associated NMDARs. However, our study provides information on the manner in which the MOR could interact with the NR1 subunit. In vitro, this association occurs through the respective C-termini; the MOR binds to NR1 subunits carrying the C1 region but shows no interaction with NR1 subunits lacking the $\mathrm{C} 1$ segment. Moreover, the MOR co-precipitated with the PSD95, indicating that this receptor associates with the

a NMDA reduces morphine analgesia: effect of serine/threonine kinase inhibition Morphine, dose-effect (+ $30 \mathrm{~min})$

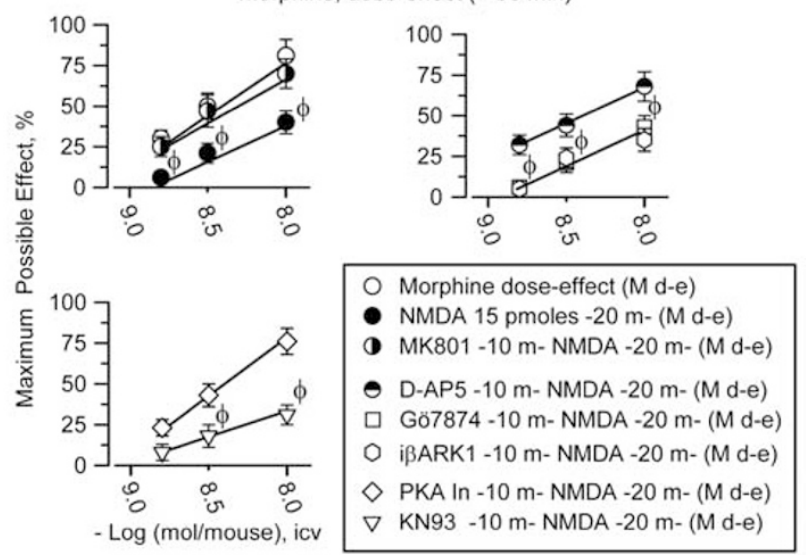

b
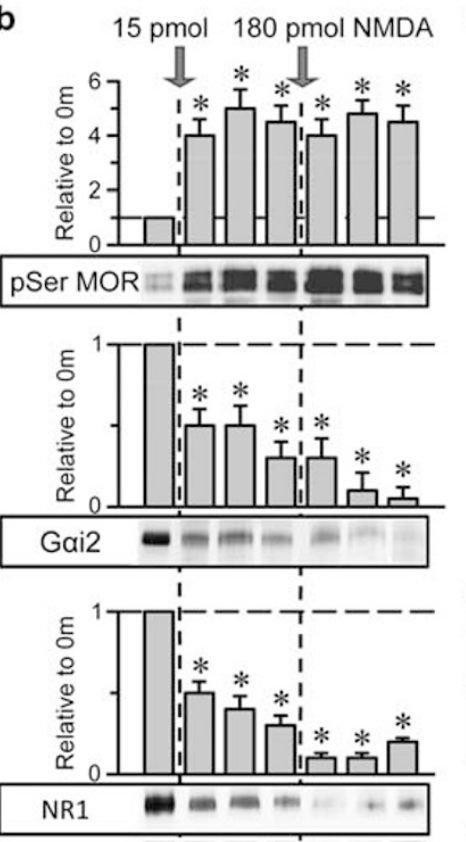

IP: MOR

$0 \mathrm{~m} 203 \mathrm{~h} 24 \mathrm{~h} 20$ 3h $24 \mathrm{~h}$ Intervals post-NMDA
C

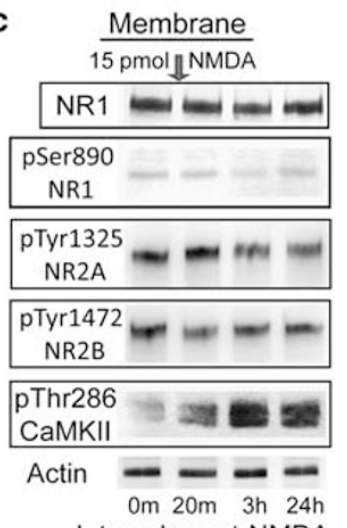

Intervals post-NMDA

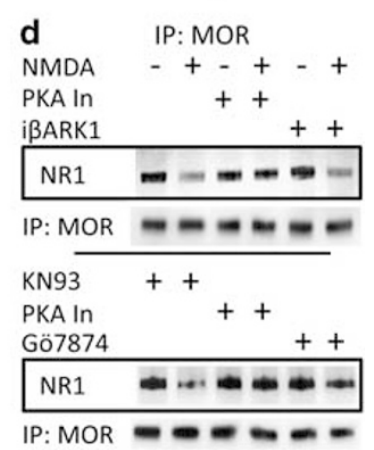

NR1 splice variant that contains the sequence for anchoring to PSD95 in the C2' segment (Kornau et al, 1995). Therefore, MOR associates with NR1 subunits with a C-terminus composed of $\mathrm{C} 0-\mathrm{C} 1-\mathrm{C} 2\left(\mathrm{C}^{\prime}\right)$ regions. Interestingly, the few GPCRs that have been reported to associate with NMDARs interact with this NR1-containing $\mathrm{C} 1$ region. Indeed, the C-termini of dopamine-D1 receptor and of group-I metabotropic glutamate receptor (mGlu5a) interact with the NR1 C1 terminal sequence (Fiorentini et al, 2003; Pei et al, 2004; Perroy et al, 2008). The binding of $\mathrm{Ca}^{2+}$ calmodulin to this cytosolic region of NR1 negatively regulates calcium flux through NMDARs. Morphine stimulates the separation of the PAG MOR-NMDAR complex probably through PKC acting on the C1 segment of the NR1 C-terminus (Chakravarthy et al, 1999), and thus enhances NMDAR calcium permeation by preventing this inhibitory binding of $\mathrm{Ca}^{2+}$-calmodulin.

Whereas, GRK2/3 controls the effects of MOR agonists, such as $\left[\mathrm{D}-\mathrm{Ala}^{2}, \mathrm{~N}-\mathrm{MePhe}^{4}, \mathrm{Gly}-\mathrm{ol}^{5}\right]$ encephalin (DAMGO), which are strong inducers of receptor internalization (Hull et al, 2010), PKC, and to some degree PKA as well, has systematically been implicated in the development of tolerance to the analgesic effects of morphine, which promotes low levels of MOR internalization (reviewed by Garzón et al, 2008). In the CNS, PKC through potentiation of NMDAR function negatively regulates morphine analgesia but not that of DAMGO (Bilsky et al, 1996) (Lu et al, 1999; Sánchez-Blázquez et al, 2009). Therefore, morphine was used in this study because its antinociception is regulated by PKC and NMDAR activity. Our recent studies indicate that, through MOR-G $\beta \gamma$-PI3K-Akt-nNOS, morphine stimulates the production of nitric oxide (NO) (Sánchez-Blázquez et al, 2010), which releases zinc ions from endogenous stores to recruit $\mathrm{PKC} \gamma$ and Raf- 1 to the HINT1 protein at the MOR C-terminus (Rodríguez-Muñoz et al, 2008; Rodríguez-Muñoz et al, 2011a). Then, $\mathrm{PKC} \gamma$

Figure 7 I $\mathrm{CV}$ NMDA desensitizes the associated MOR and separates the MOR from the NRI subunit. (a) The injection of 15 pmol icv NMDA diminished the analgesic potency of morphine. The NMDAR antagonists MK80I and D-AP5 $(0.3 \mathrm{nmol})$, the PKC inhibitor Gö7874 (I nmol), the PKA inhibitor 6-22 amide (PKA In, $5 \mathrm{nmol}$ ), the CaMKII inhibitor KN93 $(\mid 5 \mathrm{nmol})$, and the GRK2 inhibitor i $\beta$ ARKI $(100 \mathrm{nmol})$ were injected intracerebroventricularly $10 \mathrm{~min}$ before NMDA. Then, morphine was intracerebroventricularly injected 20 min after NMDA and analgesia was evaluated $30 \mathrm{~min}$ after opioid injection. ${ }^{\phi}$ Significantly different from the corresponding value of morphine analgesia obtained in the absence of the icv NMDA injection (ANOVA-Student-Newman-Keuls test; $p<0.05$ ). (b) Mice were injected with 15 and 180 pmol icv NMDA and groups of six mice each were killed at the post-NMDA intervals indicated. The PAG was removed and pooled for the ex vivo studies. The MOR was immunoprecipitated (MOR 2EL antibody) and its Ser phosphorylation (I C8 clone) was evaluated. The influence of NMDA on the association of Gai2 subunits and of NMDAR NRI subunits was also determined. (c) Protein phosphorylation related to NMDAR-CaMKII activity was studied in PAG membranes obtained from NMDA-treated mice. (d) Effect of Ser and Thr kinase inhibitors on NMDA-evoked separation of the MOR-NRI complex. The mice received the inhibitors and 10 min later $15 \mathrm{nmol}$ NMDA. The mice were killed 20 min after receiving NMDA, and the PAG was removed and pooled for the ex vivo assays. Control mice received saline instead of the inhibitor or NMDA. The MOR was immunoprecipitated (IP) and the associated NRI was measured. Further details are provided under section Materials and methods and the legend to Figure 4. 
causes MOR-NR1 separation and produces the sustained potentiation of NMDAR calcium currents by activating Src (Sánchez-Blázquez et al, 2009), and also the Raf-1-ERK1/2 cascade (Rodríguez-Muñoz et al, 2011a). Afterwards, NMDAR-regulated CaMKII promotes MOR phosphorylation and its uncoupling from regulated G-proteins (Sánchez-Blázquez et al, 2008, and references therein). The MOR-NMDAR association indicates that those concatenated processes are confined within the close environment of both receptors. PKA has also been implicated in the phosphorylation of NR1 C1 Ser897 (Tingley et al, 1997); however, our results indicate that morphine recruits $\mathrm{PKC}$ to separate both receptors in PAG neurons. In agreement with our observation, PKC phosphorylation of NR1 Ser890 promotes the dispersion of membrane NR1 subunits, which reorganize when they are de-phosphorylated. This is not observed when Ser896 or Ser897 is phosphorylated (Tingley et al, 1997).

The PKC-mediated separation of MORs from NMDARs is observed when the analgesic efficacy of morphine declines. This phenomenon starts about 3 to $6 \mathrm{~h}$ after the injection of icv morphine. Twenty-four hours later, some of the MORs in the synaptosomal membrane remain separated from NMDARs. This timing reasonably agrees with the PKCmediated activation of ERK1/2 at MORs, which leads to the enhancement of NMDAR function (Rodríguez-Muñoz et al, 2011a). After MOR separates from the NMDAR, but not before, the administration of a second dose of morphine promoted the GRK2-mediated phosphorylation of MOR Ser375, and these receptors then underwent internalization/ recycling (Rodríguez-Muñoz et al, 2007b; present study). Therefore, NR1 separation from the MOR C-terminus permits GRK2 to act on Ser/Thr residues required for internalization of the receptor. The recycling of the MOR did not help morphine to recover full analgesic potency, but brought no further tolerance even after additional administrations of the opioid (Rodríguez-Muñoz et al, 2007b). Thus, MOR signaling was kept reduced by the effect of PKCactivated NMDARs, and accordingly in morphine-tolerant mice the inhibition of PKC caused MOR dephosphorylation and re-established MOR coupling to G-proteins. The inhibition of PKC facilitated NR1 C1 dephosphorylation and probably also facilitated the inhibitory binding of $\mathrm{Ca}^{2+}$ -calmodulin to this region. Thus, morphine triggers a PKC activity, which last longer than its analgesic effect. This durable activation of PKC seems to be mediated by the morphine-induced, long-lasting enhancement of NMDAR function (Sánchez-Blázquez et al, 2009; Rodríguez-Muñoz et al, 2011b). The NMDAR/nNOS-released zinc binds to the regulatory domain of conventional $\mathrm{PKC}$ isoforms and contributes to their activation. Then, zinc ions promote PKC translocation from the soluble phase to the membrane, enhances their affinity for phorbol esters or diacylglycerol, and as high zinc stabilizes their binding to the regulatory domain, PKC activation persists for long intervals (Zalewski et al, 1990; Rodríguez-Muñoz et al, 2008; Garzón et al, 2011). Indeed, this is not a singular event; in the NMDAR environment the long-term activation of PKA has also been reported this time related to transient inhibition of the protein Ser/Thr phosphatase calcineurine (Malleret et al, 2001). As a whole, PKC inhibition reset the MOR-NMDAR system, reduced NMDAR function, and restored the capacity of morphine to produce antinociception in mice that had been rendered tolerant to morphine. Similarly, NMDAR antagonists or CaMKII inhibitors also reverse morphine tolerance, but GRK2 inhibition does not (SánchezBlázquez et al, 2008; Hull et al, 2010). These observations suggest that the priming dose of morphine triggers a late negative feedback through MOR-stimulated NMDARs and causes acute morphine tolerance that diminishes the analgesia achieved with successive doses. Although NMDARs are not involved in the regulation of analgesia produced by single doses of morphine or fentanyl in rodents, combinations of NMDAR antagonists with opioids seem to be effective to control pain in humans (Redwine and Trujillo, 2003, and references therein). It is therefore possible that MOR-associated NMDARs are silent in most situations, but when the nociceptive signal reaches a certain threshold, as in situations of neuropathic pain, NMDAR activity negatively affects the signaling capacity of the MOR and then NMDAR antagonism is beneficial to opioid analgesia.

The pharmacological activation of NMDARs also caused the separation of MOR and NR1 subunits, and, importantly, stimulated the phosphorylation and uncoupling of MORs. Under these circumstances, NMDA administration greatly diminished the efficacy of morphine in controlling nociception, similar to what is observed in situations of neuropathic pain in which there is an NMDAR hyper-function (Chapman et al, 1994; Celerier et al, 2000). There is a general agreement that PKA enhances NMDAR function in painsuffering arthritic rats (Bird et al, 2005; Fu et al, 2008). We found that NMDA-induced antagonism of morphine antinociception could be prevented by inhibiting PKA but not PKC. Therefore, PKA may be responsible for the dissociation of NR1 subunits from MORs, which occurs as a result of NMDAR activation leading to MOR Ser phosphorylation and uncoupling from G-proteins. PKA located in the PSDNMDAR complex is activated through $\mathrm{Ca}^{2+}$-calmodulindependent adenylyl cyclase and then potentiates NMDARdependent calcium currents (Chetkovich and Sweatt, 1993). PKA does not affect NMDARs that contain NR1 subunits lacking the $\mathrm{C} 1$ region (Westphal et al, 1999). Therefore, the C1 segment of the NR1 subunit, which carries the inhibitory site for $\mathrm{Ca}^{2+}$-calmodulin binding, is a common target for PKC and PKA phosphorylation. Then, NMDA-activated PKA enhances the NMDAR calcium fluxes necessary for CaMKII or nNOS activation. Therefore, this mechanism would bring about a reduction in morphine-induced antinociception, in addition to the possibility of a direct effect of PKA on MOR cytosolic residues (Chakrabarti et al, 1998). In situations in which NMDARs, through PKA, and MORs, through PKC, contribute to opioid tolerance, the simultaneous inhibition of PKC and PKA would effectively restore the antinociceptive effect of morphine (reviewed by Garzón et al, 2008).

In summary, this study has shown that in the mouse PAG the MOR and the NMDAR form a PKC/PKA-regulated association, and that these receptors could physically interact. This association is altered by the functional antagonism that exists between MOR and NMDAR signaling in pain control. Thus, morphine and NMDA recruit PKC and PKA, respectively, to promote functional changes in the associated receptor-activating or inactivating phosphorylations. 
This MOR-NMDAR association appears to be of relevance in the control of nociception and provides a significant conceptual advance as to how the NMDAR exerts its negative regulation on MOR function. This finding could be useful in the clinical management of pain states refractory to opioid treatment; for example, through the selectivity provided by bifunctional drugs that binding to the MOR reach and antagonize the function of the associated NMDAR.

\section{ACKNOWLEDGEMENTS}

This research was supported by FIS PI080417 (PS-B) and PS09/00332 (JG). MR-M is currently supported by a CIBERSAM contract, and AV-S is a pre-doctoral fellow from the Spanish Ministry of Science and Innovation. We thank Beatriz Fraile, Gabriela de Alba, and Concha Bailón for excellent technical assistance.

\section{DISCLOSURE}

The authors declare that, except for the income received from our primary employer 'Ministerio de Ciencia y Tecnología', no financial support or compensation has been received from any individual or corporate entity over the past 3 years for research or professional service, and there are no personal financial holdings that could be perceived as constituting a potential conflict of interest.

\section{REFERENCES}

Barbaro NM (1988). Studies of PAG/PVG stimulation for pain relief in humans. Prog Brain Res 77: 165-173.

Bilsky EJ, Inturrisi CE, Sadee W, Hruby VJ, Porreca F (1996). Competitive and non-competitive NMDA antagonists block the development of antinociceptive tolerance to morphine, but not to selective mu or delta opioid agonists in mice. Pain 68: 229-237.

Bird GC, Lash LL, Han JS, Zou X, Willis WD, Neugebauer V (2005). Protein kinase A-dependent enhanced NMDA receptor function in pain-related synaptic plasticity in rat amygdala neurones. J Physiol 564: 907-921.

Bittar RG, Kar-Purkayastha I, Owen SL, Bear RE, Green A, Wang S et al (2005). Deep brain stimulation for pain relief: a metaanalysis. J Clin Neurosci 12: 515-519.

Celerier E, Rivat C, Jun Y, Laulin JP, Larcher A, Reynier P et al (2000). Long-lasting hyperalgesia induced by fentanyl in rats: preventive effect of ketamine. Anesthesiology 92: 465-472.

Chakrabarti S, Law PY, Loh HH (1998). Distinct differences

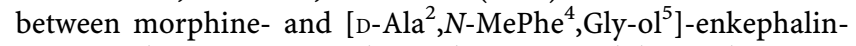
mu-opioid receptor complexes demonstrated by cyclic AMPdependent protein kinase phosphorylation. J Neurochem 71: 231-239.

Chakravarthy B, Morley P, Whitfield J (1999). $\mathrm{Ca}^{2+}$-calmodulin and protein kinase Cs: a hypothetical synthesis of their conflicting convergences on shared substrate domains. Trends Neurosci 22: 12-16.

Chapman V, Haley JE, Dickenson AH (1994). Electrophysiologic analysis of preemptive effects of spinal opioids on $N$-methyl-Daspartate receptor-mediated events. Anesthesiology 81: 1429-1435.

Chen L, Huang LY (1991). Sustained potentiation of NMDA receptor-mediated glutamate responses through activation of protein kinase C by a $\mu$ opioid. Neuron 7: 319-326.
Chetkovich DM, Sweatt JD (1993). NMDA receptor activation increases cyclic AMP in area CA1 of the hippocampus via calcium/calmodulin stimulation of adenylyl cyclase. J Neurochem 61: 1933-1942.

Commons KG, van Bockstaele EJ, Pfaff DW (1999). Frequent colocalization of mu opioid and NMDA-type glutamate receptors at postsynaptic sites in periaqueductal gray neurons. J Comp Neurol 408: 549-559.

Fiorentini C, Gardoni F, Spano P, Di LM, Missale C (2003). Regulation of dopamine D1 receptor trafficking and desensitization by oligomerization with glutamate $\mathrm{N}$-methyl-D-aspartate receptors. J Biol Chem 278: 20196-20202.

Fu Y, Han J, Ishola T, Scerbo M, Adwanikar H, Ramsey C et al (2008). PKA and ERK, but not PKC, in the amygdala contribute to pain-related synaptic plasticity and behavior. Mol Pain 4: 26.

Garzón J, Rodríguez-Muñoz M, López-Fando A, Sánchez-Blázquez P (2005a). Activation of $\mu$-opioid receptors transfers control of $\mathrm{G} \alpha$ subunits to the regulator of G-protein signaling RGS9-2: role in receptor desensitization. J Biol Chem 280: 8951-8960.

Garzón J, Rodriguez-Muñoz M, Sánchez-Blázquez P (2005b). Morphine alters the selective association between mu-opioid receptors and specific RGS proteins in mouse periaqueductal gray matter. Neuropharmacology 48: 853-868.

Garzón J, Rodriguez-Muñoz M, Sánchez-Blázquez P (2008). Do pharmacological approaches that prevent opioid tolerance target different elements in the same regulatory machinery? Curr Drug Abuse Rev 1: 222-238.

Garzón J, Rodríguez-Muñoz M, Vicente-Sánchez A, Bailón C, Martínez-Murillo R, Sánchez-Blázquez P (2011). RGSZ2 binds to the nNOS PDZ domain to regulate mu-opioid receptor-mediated potentiation of the NMDAR-CaMKII pathway. Antioxid Redox Signal 15: 873-887.

Glass MJ, Vanyo L, Quimson L, Pickel VM (2009). Ultrastructural relationship between $N$-methyl-D-aspartate-NR1 receptor subunit and mu-opioid receptor in the mouse central nucleus of the amygdala. Neuroscience 163: 857-867.

Gulya K, Krivan M, Nyolczas N, Sarnyai Z, Kovacs GL (1988). Central effects of the potent and highly selective mu opioid antagonist D-Phe-Cys-Tyr-D-Trp-Orn-Thr-Pen-Thr-NH2 (CTOP) in mice. Eur J Pharmacol 150: 355-360.

Hisatsune C, Umemori H, Inoue T, Michikawa T, Kohda K, Mikoshiba K et al (1997). Phosphorylation-dependent regulation of $N$-methyl-D-aspartate receptors by calmodulin. J Biol Chem 272: 20805-20810.

Hull LC, Llorente J, Gabra BH, Smith FL, Kelly E, Bailey C et al (2010). The effect of protein kinase $C$ and $G$ protein-coupled receptor kinase inhibition on tolerance induced by mu-opioid agonists of different efficacy. J Pharmacol Exp Ther 332: 1127-1135.

Inoue M, Mishina M, Ueda $H$ (2003). Locus-specific rescue of GluRe1 NMDA receptors in mutant mice identifies the brain regions important for morphine tolerance and dependence. J Neurosci 23: 6529-6536.

Kornau HC, Schenker LT, Kennedy MB, Seeburg PH (1995). Domain interaction between NMDA receptor subunits and the postsynaptic density protein PSD-95. Science 269: 1737-1740.

Kow LM, Commons KG, Ogawa S, Pfaff DW (2002). Potentiation of the excitatory action of NMDA in ventrolateral periaqueductal gray by the mu-opioid receptor agonist, DAMGO. Brain Res 935: 87-102.

Koyama S, Akaike N (2008). Activation of mu-opioid receptor selectively potentiates NMDA-induced outward currents in rat locus coeruleus neurons. Neurosci Res 60: 22-28.

Lipton SA (2006). Paradigm shift in neuroprotection by NMDA receptor blockade: memantine and beyond. Nat Rev Drug Discov 5: $160-170$.

Lu WY, Xiong ZG, Lei S, Orser BA, Dudek E, Browning MD et al (1999). G-protein-coupled receptors act via protein kinase C and Src to regulate NMDA receptors. Nat Neurosci 2: 331-338. 
Maeng S, Zarate Jr CA (2007). The role of glutamate in mood disorders: results from the ketamine in major depression study and the presumed cellular mechanism underlying its antidepressant effects. Curr Psychiatry Rep 9: 467-474.

Malleret G, Haditsch U, Genoux D, Jones MW, Bliss TV, Vanhoose $\mathrm{AM}$ et al (2001). Inducible and reversible enhancement of learning, memory, and long-term potentiation by genetic inhibition of calcineurin. Cell 104: 675-686.

Mansour A, Khachaturian H, Lewis ME, Akil H, Watson SJ (1988). Anatomy of CNS opioid receptors. Trends Neurosci 11: 308-314.

Marinelli S, Vaughan CW, Schnell SA, Wessendorf MW, Christie MJ (2002). Rostral ventromedial medulla neurons that project to the spinal cord express multiple opioid receptor phenotypes. J Neurosci 22: 10847-10855.

Martin G, Nie Z, Siggins GR (1997). mu-Opioid receptors modulate NMDA receptor-mediated responses in nucleus accumbens neurons. J Neurosci 17: 11-22.

Mechri A, Saoud M, Khiari G, d'Amato T, Dalery J, Gaha L (2001). Glutaminergic hypothesis of schizophrenia: clinical research studies with ketamine. Encephale 27: 53-59.

Mizoguchi H, Watanabe C, Yonezawa A, Sakurada S (2009). New therapy for neuropathic pain. Int Rev Neurobiol 85: 249-260.

Mori H, Mishina M (1995). Structure and function of the NMDA receptor channel. Neuropharmacology 34: 1219-1237.

Narita M, Hashimoto K, Amano T, Narita M, Niikura K, Nakamura A et al (2008). Post-synaptic action of morphine on glutamatergic neuronal transmission related to the descending antinociceptive pathway in the rat thalamus. J Neurochem 104: 469-478.

Olverman HJ, Jones AW, Watkins JC (1984). L-glutamate has higher affinity than other amino acids for [3H]-D-AP5 binding sites in rat brain membranes. Nature 307: 460-462.

Owen SL, Green AL, Nandi DD, Bittar RG, Wang S, Aziz TZ (2007). Deep brain stimulation for neuropathic pain. Acta Neurochir Suppl 97: 111-116.

Palmer GC (2001). Neuroprotection by NMDA receptor antagonists in a variety of neuropathologies. Curr Drug Targets 2: $241-271$.

Pan YX (2005). Diversity and complexity of the mu opioid receptor gene: alternative pre-mRNA splicing and promoters. DNA Cell Biol 24: 736-750.

Pei L, Lee FJ, Moszczynska A, Vukusic B, Liu F (2004). Regulation of dopamine D1 receptor function by physical interaction with the NMDA receptors. J Neurosci 24: 1149-1158.

Perroy J, Raynaud F, Homburger V, Rousset MC, Telley L, Bockaert J et al (2008). Direct interaction enables cross-talk between ionotropic and group I metabotropic glutamate receptors. J Biol Chem 283: 6799-6805.

Przewlocki R, Parsons KL, Sweeney DD, Trotter C, Netzeband JG, Siggins GR et al (1999). Opioid enhancement of calcium oscillations and burst events involving NMDA receptors and L-type calcium channels in cultured hippocampal neurons. J Neurosci 19: 9705-9715.

Redwine KE, Trujillo KA (2003). Effects of NMDA receptor antagonists on acute mu-opioid analgesia in the rat. Pharmacol Biochem Behav 76: 361-372.

Rodríguez-Muñoz M, de la Torre-Madrid E, Gaitán G, SánchezBlázquez P, Garzón J (2007a). RGS14 prevents morphine from internalizing mu-opioid receptors in periaqueductal gray neurons. Cell Signal 19: 2558-2571.

Rodríguez-Muñoz M, de la Torre-Madrid E, Sánchez-Blázquez P, Garzón J (2007b). Morphine induces endocytosis of neuronal mu-opioid receptors through the sustained transfer of Galpha subunits to RGSZ2 proteins. Mol Pain 3: 19.

Rodríguez-Muñoz M, de la Torre-Madrid E, Sánchez-Blázquez P, Garzón J (2011a). NO-released zinc supports the simultaneous binding of Raf-1 and PKC $\gamma$ cysteine-rich domains to HINT1 protein at the mu-opioid receptor. Antioxid Redox Signal 14: $2413-2425$

Rodríguez-Muñoz M, de la Torre-Madrid E, Sánchez-Blázquez P, Wang JB, Garzón J (2008). NMDAR-nNOS generated zinc recruits $\mathrm{PKC} \gamma$ to the HINT1-RGS17 complex bound to the $\mathrm{C}$ terminus of mu-opioid receptors. Cell Signal 20: 1855-1864.

Rodríguez-Muñoz M, Sánchez-Blázquez P, Vicente-Sánchez A, Bailón C, Martín-Aznar B, Garzón J (2011b). The histidine triad nucleotide-binding protein 1 supports mu-opioid receptorglutamate NMDA receptor cross-regulation. Cell Mol Life Sci; doi:10.1007/s00018-010-0598-x.

Rusin KI, Randic M (1991). Modulation of NMDA-induced currents by mu-opioid receptor agonist DAGO in acutely isolated rat spinal dorsal horn neurons. Neurosci Lett 124: 208-212.

Sánchez-Blázquez P, Rodríguez-Muñoz M, de la Torre-Madrid E, Garzón J (2009). Brain-specific G $\alpha z$ interacts with Src tyrosine kinase to regulate mu-opioid receptor-NMDAR signaling pathway. Cell Signal 21: 1444-1454.

Sánchez-Blázquez P, Rodríguez-Muñoz M, Garzón J (2010). Muopioid receptors transiently activate the Akt-nNOS pathway to produce sustained potentiation of PKC-mediated NMDARCaMKII signaling. PLoS One 5: e11278.

Sánchez-Blázquez P, Rodríguez-Muñoz M, Montero C, de la TorreMadrid E, Garzón J (2008). Calcium/calmodulin-dependent protein kinase II supports morphine antinociceptive tolerance by phosphorylation of glycosylated phosducin-like protein. Neuropharmacology 54: 319-330.

Saper CB, Sawchenko PE (2003). Magic peptides, magic antibodies: guidelines for appropriate controls for immunohistochemistry. J Comp Neurol 465: 161-163.

Shyu YJ, Hiatt SM, Duren HM, Ellis RE, Kerppola TK, Hu CD (2008). Visualization of protein interactions in living Caenorhabditis elegans using bimolecular fluorescence complementation analysis. Nat Protoc 3: 588-596.

Sigtermans MJ, van Hilten JJ, Bauer MC, Arbous MS, Marinus J, Sarton EY et al (2009). Ketamine produces effective and longterm pain relief in patients with Complex Regional Pain Syndrome Type 1. Pain 145: 304-311.

Tingley WG, Ehlers MD, Kameyama K, Doherty C, Ptak JB, Riley CT et al (1997). Characterization of protein kinase A and protein kinase C phosphorylation of the $N$-methyl-D-aspartate receptor NR1 subunit using phosphorylation site-specific antibodies. J Biol Chem 272: 5157-5166.

Trujillo KA (2002). The neurobiology of opiate tolerance, dependence and sensitization: mechanisms of NMDA receptordependent synaptic plasticity. Neurotox Res 4: 373-391.

Westphal RS, Tavalin SJ, Lin JW, Alto NM, Fraser ID, Langeberg LK et al (1999). Regulation of NMDA receptors by an associated phosphatase-kinase signaling complex. Science 285: 93-96.

Wong EH, Kemp JA, Priestley T, Knight AR, Woodruff GN, Iversen LL (1986). The anticonvulsant MK-801 is a potent $N$-methyl-Daspartate antagonist. Proc Natl Acad Sci USA 83: 7104-7108.

Zalewski PD, Forbes IJ, Giannakis C, Cowled PA, Betts WH (1990). Synergy between zinc and phorbol ester in translocation of protein kinase C to cytoskeleton. FEBS Lett 273: 131-134.

Zukin RS, Bennett MV (1995). Alternatively spliced isoforms of the NMDARI receptor subunit. Trends Neurosci 18: 306-313.

Supplementary Information accompanies the paper on the Neuropsychopharmacology website (http://www.nature.com/npp) 